\title{
Perbedaan Persepsi Wisatawan Perempuan dan Laki-laki Mancanegara terhadap Keselamatan dan Keamanan Wisata di Kota Yogyakarta
}

\author{
Junanto \\ Program Studi Pariwisata, Fakultas Ilmu Budaya, Universitas Gadjah Mada \\ Email: junanto@mail.ugm.ac.id
}

\begin{abstract}
Tourism safety and security is one of the most important aspects of the tourism industry. Bad perception of tourism safety and security could greatly hinder the growth of tourists in a city. Gender, which is a topic highly related to tourism safety and security, has often been debated among researchers hence is a very intriguing issue to examine further. Therefore, research that analyses the safety and security of Yogyakarta city from the perspective of gender is extremely valuable and important. This research uses a quantitative descriptive method with a total of 102 respondents to figure out their perception toward tourism safety and security in Yogyakarta City. The quota sampling method is used to obtain a balanced proportion of male and female respondents in this research. The result shows that foreign tourists perceive Yogyakarta City as "Safe" in tourism safety and security. However, out of four dimensions that are used in this research, one dimension that discusses traffic safety in Yogyakarta has been perceived as "Unsafe" by foreign tourists. From the gender perspective, data shows that male foreign tourists perceived Yogyakarta as a safer tourist destination than female foreign tourists.
\end{abstract}

Keyword: Tourism Safety and Security, Gender, Kota Yogyakarta

\section{Pendahuluan}

Keselamatan dan keamanan wisata (tourism safety and security) merupakan salah satu unsur paling vital dalam dunia pariwisata. Kesuksesan maupun kegagalan suatu destinasi wisata sangat tergantung dengan kemampuan sebuah destinasi dalam memberikan rasa aman di destinasi tersebut (UNWTO, 1996)1. Hal tersebut dikarenakan keselamatan dan keamanan wisata merupakan salah satu faktor yang mempengaruhi pengambilan keputusan wisatawan dalam berkunjung ke suatu destinasi (Pearce, 1988: 28; Mansfeld, 2006: 271279). Hasil penelitian dari George (2002: 575-585) juga menyatakan bahwa terdapat keterkaitan yang kuat antara persepsi keamanan dan kenyamanan destinasi wisatawan terhadap jumlah kunjungan wisatawan ke suatu destinasi. Sebuah destinasi dengan citra keselamatan dan keamanan yang rendah akan berdampak besar pada citra destinasi tersebut secara umum sehingga dalam keadaan yang serius dapat menyebabkan menurunnya kunjungan wisatawan ke destinasi secara drastis (Ryan, 1993: 173-183). Maka dapat disimpulkan bahwa persepsi wisatawan akan keselamatan dan keamanan wisata pada suatu destinasi sangat krusial sehingga penelitian mengenai bidang ini sangat diperlukan.

Enz (2009: 553-560) mendefinisikan keselamatan dan keamanan wisata sebagai kondisi atau rasa aman pada seorang individu baik secara materi maupun fisik sehingga tidak terjadi kerugian pada individu tersebut. Masalah mengenai keamanan dan keselamatan kerap menjadi bahasan 
dalam dunia pariwisata karena menurut sejumlah ahli (Fujii dan Mak 1980: 42 -56; Chesney dan Lind 1986: 78-96), wisatawan sangat sering menjadi target dari kriminalitas dan ketidakamanan dibandingkan dengan penduduk setempat karena mereka sering dianggap sebagai orang yang mempunyai uang dan barang berharga (kamera, jam tangan, perhiasan, kartu kredit, dan lainnya) yang banyak. Ditambah lagi, sejumlah besar wisatawan memiliki karakteristik yang menonjol yang dapat dilihat dari cara berpakaian mereka dan perbedaan kelakuan membuat mereka semakin rentan terhadap tindakan kriminal dan ketidakamanan. Penelitian ini mempunyai peranan penting untuk mengidentifikasikan apakah faktor gender perlu dipertimbangkan dalam pembangunan pariwisata khususnya untuk wisatawan mancanegara karena keselamatan dan keamanan wisata kini telah menjadi sebuah aspek yang sangat diperhatikan dalam industri pariwisata (Reisinger dan Crotts, 2009: 800).

Membahas mengenai keselamatan dan keamanan wisata, sejumlah ahli telah berpendapat bahwa gender merupakan salah satu faktor yang penting untuk dikaji. Gender sering menjadi faktor penting dalam penentuan destinasi wisata. Beberapa penelitian mengungkapkan bahwa perempuan lebih rawan terhadap serangan dan ancaman saat berwisata (Resinger \& Crotts, 2009: 800; Gustafson, 1998: 805-811, Park \& Reisinger, 2010: 1-24). Tetapi di sisi lain, juga terdapat pendapat bahwa pariwisata tidak sepenuhnya dipengaruhi oleh gender melainkan oleh faktor lain seperti budaya, latar belakang maupun peran wisatawan (Lepp \& Gibson, 2003: 606-624; Stants dkk, 2006: 121-132). Oleh karena itu, peneliti ingin mengkaji lebih lanjut untuk melihat bagaimana persepsi keselamatan dan keamanan wisata dipengaruhi oleh gender khususnya di Yogyakarta.

Kota Yogyakarta yang menjadi merupakan satu-satunya kotamadya dan ibukota dari Provinsi Daerah Istimewa Yogyakarta. Dari lima kabupaten dan satu kotamadya di DIY, Kota Yogyakarta merupakan wilayah dengan tingkat kunjungan wisatawan mancanegara tertinggi jumlah 297.695 orang dan diikuti oleh Kabupaten Sleman dengan jumlah 262.071, Kabupaten Gunung Kidul dengan jumlah 21.067 orang, Kabupaten Bantul dengan jumlah 10.493 orang, dan Kabupaten Kulon
Progo dengan jumlah 10.455 orang (Statistik Kepariwisataan Yogyakarta, 2017). Tidak hanya memiliki tingkat kunjungan wisatawan mancanegara tertinggi, Kota Yogyakarta juga memiliki objek wisata yang tingkat kunjungannya paling tinggi di DIY yaitu Keraton Yogyakarta dengan angka 130,139 orang wisatawan mancanegara. Kota Yogyakarta juga merupakan tempat ikon pariwisata DIY berada yaitu kawasan Malioboro.

Dari tingkat kriminalitas, Kota Yogyakarta menempati peringkat kedua sebagai wilayah dengan kerawanan kriminalitas tertinggi di DIY setelah Kabupaten Sleman. Pada tahun 2018, tercatat 1,116 kasus kriminalitas yang meningkat dari 1,092 kasus dari tahun 2017 (Kepolisian Daerah DIY, 2018). Kota Yogyakarta memiliki peranan yang sangat krusial sebagai destinasi wisata bagi wisatawan mancanegara di DIY. Jika Kota Yogyakarta memiliki citra keselamatan dan keamanan yang buruk bagi wisatawan mancanegara, maka hal tersebut akan berdampak langsung pada industri pariwisata di DIY. Walau demikian, masih belum terdapat penelitian yang mengukur persepsi wisatawan mancanegara terhadap keselamatan dan keamanan wisatawan khususnya dari segi sudut pandang gender, yang sering menjadi perdebatan antar ilmuwan. Oleh sebab itu, peneliti merasa perlu dilakukan penelitian terkait perbedaan persepsi wisatawan perempuan dan laki-laki mancanegara terhadap keselamatan dan keamanan wisata di Kota Yogyakarta.

\section{Kerangka Teori}

Pariwisata telah didefinisikan oleh berbagai ahli pariwisata sebagai perpindahan sementara manusia dari wilayah asalnya ke wilayah baru, tanpa memiliki kaitan pada pekerjaan maupun penghasilan pendapatan dan tidak menempati daerah tersebut secara permanen, serta terdapat amenitas serta fasilitas untuk memenuhi kebutuhan mereka (United Nation, 2010; Mathieson dan Wall: 10). Berdasarkan teori tersebut, dapat disimpulkan bahwa wisatawan perlu melakukan perpindahan lokasi geografis dari tempat asal ke tempat lainnya. Di sisi lain, Shin (2006: 411) menyatakan bahwa setiap menit dari setiap hari, tindakan kriminal ataupun kekerasan terjadi di sebuah lokasi di dunia. Secara global, belum ada negara yang memiliki 
tingkat kriminal yang mencapai angka nol, hal tersebut dapat diartikan bahwa jika seseorang melakukan kegiatan wisata dengan mengunjungi tempat baru, maka terdapat risiko di mana kejahatan mungkin bisa terjadi pada dirinya, tentu setiap daerah memiliki kemungkinan atau tingkat persentase yang berbeda. Selain kriminalitas, hal lain yang dapat mengancam keselamatan dan keamanan wisatawan dapat berupa ketidakstabilan politik, bencana alam, epidemik dan pandemik (Kovari \& Zimanyi, 2011: 59). Yang dkk (2016: 89) berpendapat bahwa risiko dan pariwisata adalah dua hal yang tidak dapat dipisahkan, karena keputusan berwisata mengindikasikan risiko dan ketidakpastian, karena orang yang berwisata akan mengunjungi tempat yang memiliki lingkungan sosial yang berbeda. Selain itu, Williams \& Bala (2013: 209-211) menyimpulkan bahwa sebagai sebuah industri yang menawarkan jasa, pariwisata memiliki sifat tidak dapat dilihat, tidak dapat dipisahkan, heterogen, dan memberikan kenangan, di mana di ciri tersebut terdapat unsur ketidakpastian dan risiko dalam melakukan perjalanan wisata. Dalam konteks lain, kajian terkait keselamatan dan keamanan perlu dilakukan di industri pariwisata karena wisatawan sering menjadi korban dari tindakan kriminalitas akibat perbedaan budaya yang berwujud (Fujii and Mak 1980: 42 -56).

Keselamatan dan keamanan wisata tentu memiliki peranan penting dalam menjaga kelancaran industri pariwisata. Kegagalan dalam menciptakan kondisi maupun persepsi aman akan mempunyai dampak yang sangat besar terhadap industri dan juga mempengaruhi para pemangku kebijakan. Dalam buku Tourism, Safety \& Security (2006: 6-9) oleh Mansfeld \& Pizam, telah dijelaskan bahwa jika terdapat persepsi terhadap destinasi wisata yang kurang baik, maka akan mempengaruhi perilaku wisatawan dan keputusan wisatawan dalam berwisata dalam sebuah destinasi seperti hilangnya niat kunjungan, terjadi pembatalan wisata, dan proyeksi citra destinasi ke depannya. Dari sejumlah dampak yang dipaparkan, dapat disimpulkan bahwa penting untuk senantiasa menjaga keselamatan dan keamanan wisata agar tidak merugikan industri pariwisata suatu destinasi.

Jika keselamatan dan keamanan wisata dikaitkan dengan gender, maka terdapat banyak perdebatan di kalangan akademisi terkait perbedaan perspektif wisatawan laki-laki dan perempuan terhadap risiko berwisata. Reisinger dan Crotts (2009:800) menyatakan bahwa penting untuk mengidentifikasi perbedaan kebutuhan wisatawan laki-laki dan perempuan terhadap keselamatan dan keamanan wisata karena hal tersebut akan mempengaruhi pengalaman berwisata mereka. Peneliti lain seperti Gustafson (1998: 805-811) dan Park \& Reisinger (2010: 1-24) memiliki pendapat yang sama di mana perempuan dan laki-laki memiliki pandangan terhadap risiko yang berbeda karena beberapa risiko lebih rentan terjadi di perempuan, seperti kekerasan seksual yang disebabkan oleh dominasi fisik oleh laki-laki. Namun, terdapat juga teori yang bertolak belakang dengan teori sebelumnya dari sejumlah ahli. Lepp \& Gibson (2003: 606-624) menyatakan gender tidak mempunyai pengaruh yang besar terhadap keamanan dan keselamatan berwisata karena masih terdapat banyak faktor lain seperti latar belakang dan budaya wisatawan. Pendapat tersebut didukung oleh ahli lain seperti penelitian Staats dkk (2006: 121-132) yang menyatakan perempuan tidak lebih takut dan khawatir saat berwisata dibandingkan pria. Perbedaan teori tersebut perlu dibuktikan dengan berbagai studi kasus di berbagai daerah agar dapat menarik kesimpulan yang lebih objektif. Maka penelitian terkait perbedaan perspektif wisatawan laki-laki dan perempuan di berbagai lokasi yang spesifik perlu dilakukan.

Dalam konteks gender, Yang dkk (2016: 89-100) telah melakukan sebuah tinjauan pustaka secara sistematis terkait risiko berwisata dan gender di pariwisata. Hasil tersebut menyimpulkan bahwa lintasan mengenai risiko berwisata dan gender memiliki karakteristik yang menunjukan sampel dan konteks masih berorientasi pada dunia barat. Kurangnya investigasi serta kerangka teori terkait gender dan risiko berwisata juga merupakan kelemahan dari penelitian dari keselamatan dan keamanan wisata dan kaitannya terhadap gender. Maka, dibutuhkan juga penelitian yang dilakukan di negara non-barat serta mencangkup studi kasus untuk mengurangi kelemahan tersebut.

Dalam mengembangkan indikator persepsi wisatawan terhadap keselamatan wisata, peneliti mengacu pada penelitian George (2002); Barker dkk(2003); Batra (2008). Ketiga penelitian ini meneliti langsung terkait persepsi wisatawan 
terhadap keselamatan dan keamanan wisata dengan lokus dan fokus yang berbeda. Indikator keselamatan dan keamanan wisata pertama dikembangkan oleh George yang meneliti persepsi wisatawan terhadap keselamatan dan keamanan wisata ketika berkunjung ke Cape Town. Indikator keselamatan dan keamanan wisata yang digunakan berjumlah lima yaitu berkaitan dengan berwisata di kota pada pagi hari, berjalan di jalan raya pada malam hari, menggunakan transportasi umum, dan pengguna jalan kaki.

Indikator terkait keselamatan dan keamanan wisata kemudian dikembangkan lebih lanjut oleh Barker dkk yang meneliti persepsi pengunjung terkait keamanan ketika berwisata ke sebuah acara khusus dengan studi kasus 2000 America's Cup di Auckland, Selandia Baru. Dalam penelitian ini, indikator yang dikembangkan lebih holistik dan memperhatikan detail yang lebih rinci seperti kriminalitas, keramahtamahan penduduk, kenyamanan dari segi budaya, ketersediaan sarana yang menjamin keselamatan dan keamanan wisata, dan lain-lain. Peneliti tidak menggunakan semua indikator yang dikembangkan oleh Barker dkk karena penelitian ini tidak difokuskan ke acara/ event dan juga menyesuaikan indikator dengan lokus Kota Yogyakarta. Indikator yang digunakan dalam penelitian ini berdasarkan penelitian Barker berjumlah 14 yaitu berkaitan dengan kunjungan ke daerah terpelosok, berwisata seorang diri, pembawaan barang berharga, kejahatan lokal, kejahatan seksual secara verbal, non-verbal, serta fisik, polisi dan petugas keamanan, kenyamanan dalam ras, pelayanan dan barang di tempat wisata.

Salah satu penelitian terkait keselamatan dan keamanan wisata dengan lokus Asia Tenggara dapat ditemukan di penelitian Batra (2008) yang meneliti persepsi keselamatan pribadi dan kemungkinan terjadi tindak kriminalitas terhadap turis asing ketika berkunjung ke Bangkok. Pada penelitian ini, terdapat banyak indikator yang telah digunakan oleh peneliti sebelumnya karena Batra mengembangkan indikator yang telah digunakan oleh George dan Barker tetapi tidak seluruhnya. Dalam penelitiannya, Batra telah mengelompokkan indikator-indikatornya menjadi beberapa dimensi yaitu persepsi turis terhadap berwisata ke Bangkok secara umum, persepsi wisatawan terhadap keselamatan dan keamanan di Bangkok, dan kekhawatiran turis terhadap kriminalitas di Bangkok. Beberapa indikator baru juga dapat ditemukan di penelitian ini terutama terkait budaya dan keramahtamahan masyarakat sekitar seperti kekhawatiran diganggu karena unsur ras dan kekhawatiran berinteraksi dengan masyarakat lokal. Hal tersebut diperlukan karena rasa asing terhadap suatu destinasi dan tidak ramahnya penduduk lokal dapat menjadi implikasi rasa takut dan meningkatkan kerentanan wisatawan terhadap kejahatan. Indikator yang ada juga disesuaikan dengan lokus penelitian peneliti di Kota Yogyakarta. Peneliti menggunakan lima indikator yang terdapat dalam penelitian ini yang berupa ketersediaan informasi keamanan pariwisata, keamanan pejalan kaki, ketersediaan papan petunjuk arah, kenyamanan dalam menggunakan bahasa daerah, dan kenyamanan dalam berinteraksi dengan masyarakat lokal.

\section{Metode Penelitian}

Penelitian ini merupakan penelitian kuantitatif yang bersifat deskriptif(Bogdan dan Biklen, 1982). Sesuai dengan metode penelitian tersebut, maka penelitian ini membandingkan tingkat persetujuan wisatawan laki-laki dan perempuan terhadap persepsi mengenai keselamatan dan keamanan wisata melalui penyebaran kuesioner dan disajikan dengan menggunakan deskriptif. Selain gender, tiga karakteristik wisatawan mancanegara yang berupa asal benua, usia, dan lama tinggal juga akan dideskripsikan untuk memperoleh data yang lebih mendetail.

Pengumpulan data dalam penelitian dilakukan melalui penyebaran kuesioner dengan teknik Quota Sampling agar mendapatkan proporsi responden antara wisatawan perempuan dan laki-laki yang seimbang. Kuesioner dibagikan kepada 102 wisatawan mancanegara di empat destinasi dengan tingkat kunjungan tertinggi di Kota Yogyakarta yaitu Keraton Yogyakarta, Taman Sari, Pagelaran Keraton, dan Makam Raja Imogiri, Kotagede. Penentuan sampel dilakukan secara acak untuk mendapat representasi wisatawan mancanegara yang beragam.

Analisis data dibagi menjadi tiga bagian dalam penelitian ini: Profil wisatawan mancanegara, Persepsi wisatawan mancanegara 
secara keseluruhan, dan Persepsi wisatawan berdasarkan karakeristik. Analisis akan dilakukan dengan mencari nilai rata-rata (mean score) yang berasal dari perhitungan frekuensi (fi) responden dan dikalikan dengan nilai bobot (xi) pada setiap respon jawaban. Nilai bobot yang digunakan dalam penelitian ini adalah "Sangat Tidak Setuju (STS)" dengan nilai bobot 1, "Tidak Setuju (TS)" dengan nilai bobot 2, "Setuju (S)" dengan nilai bobot 3, dan "Sangat Setuju (SS)" dengan nilai bobot 4 .

Setelah mendapatkan nilai rata-rata, analisis akan dilakukan berdasarkan metode deskriptif yang berdasarkan rentang skala yang dikembangkan oleh Umar (1998) dengan formula sebagai berikut: sehingga mendapatkan hasil berupa:

$$
R S=\frac{m-1}{m}
$$

Keterangan: $m=$ jumlah alternatif jawaban tiap iter

Tabel 1. Interpretasi Skala Penilaian

\begin{tabular}{|c|c|}
\hline Skala Penilaian & Kriteria \\
\hline $1,00-1,75$ & Sangat tidak aman \\
\hline $1,76-2,50$ & Tidak aman \\
\hline $2,51-3,25$ & Aman \\
\hline $3,26-4,00$ & Sangat aman \\
\hline
\end{tabular}

Sumber: Umar (1998)

Dari tabel 1, apat diketahui bahwa jika nilai rata-rata yang diperoleh masing-masing item semakin mendekati angka 4,00, maka semakin wisatawan mempersepsi bahwa Yogyakarta adalah tempat yang aman untuk wisatawan. Sebaliknya, apabila nilai rata-rata semakin mendekati angka 1,00, maka wisatawan mempersepsi Kota Yogyakarta sebagai tempat yang tidak aman bagi wisatawan.

\section{Hasil dan Pembahasan}

\subsection{Deskripsi Karakteristik Responden}

Responden yang terdiri dari wisatawan mancanegara dalam penelitian ini terdiri dari 51 wisatawan lakilaki mancanegara dan 51 wisatawan perempuan mancanegara. Wisatawan mancanegara sebagian besar berasal dari Eropa dengan persentase $62.75 \%$ dan diikuti oleh wisatawan Asia dengan persentase $17.65 \%$. Berdasarkan usia, responden didominasi oleh wisatawan mancanegara dengan kelompok umur 18-24 dan 25-31 dengan persentase 39,22\% dan $29,41 \%$ secara berurutan. Sedangkan untuk lama tinggal, $62.75 \%$ responden telah menetap selama 1-3 hari dan 17,65\% responden telah menetap selama 4-6 hari di Kota Yogyakarta

Tabel 2. Karakteristik Responden

\begin{tabular}{|c|c|c|}
\hline Karakteristik & $\mathrm{n}$ & $\%$ \\
\hline \multicolumn{3}{|c|}{ Gender } \\
\hline Laki-laki & 51 & $50 \%$ \\
\hline Perempuan & 51 & $50 \%$ \\
\hline Benua Asal \\
\hline Afrika & 1 & $0,98 \%$ \\
\hline Amerika & 12 & $11,76 \%$ \\
\hline Asia & 18 & $17,65 \%$ \\
\hline Australia & 7 & $6,86 \%$ \\
\hline Eropa & 64 & $62,75 \%$ \\
\hline 17 & 1 & $0,98 \%$ \\
\hline $18-24$ & 40 & $39,22 \%$ \\
\hline $25-31$ & 30 & $29,41 \%$ \\
\hline $32-38$ & 18 & $17,65 \%$ \\
\hline $39-45$ & 2 & $1,96 \%$ \\
\hline $46-52$ & 6 & $5,88 \%$ \\
\hline 53 & 5 & $4,90 \%$ \\
\hline \multicolumn{2}{|c|}{ Lama Tinggal } \\
\hline $1-3$ & 64 & $62,75 \%$ \\
\hline $4-6$ & 18 & $17,65 \%$ \\
\hline $7-9$ & 5 & $4,90 \%$ \\
\hline $10-12$ & 0 & $0 \%$ \\
\hline $13-15$ & 5 & $4,90 \%$ \\
\hline 16 & 10 & $9,80 \%$ \\
\hline &
\end{tabular}

4.2 Persepsi Wisatawan Mancanegara Terhadap Keselamatan dan Keamanan Wisata di Kota Yogyakarta

Berdasarkan hasil analisis pada tabel 3, data menunjukan bahwa nilai rata-rata keempat dimensi terkait persepsi wisatawan terhadap keselamatan dan keamanan wisata di Yogyakarta adalah 2,85. 
Dengan demikian, dapat disimpulkan bahwa wisatawan mancanegara merasa Kota Yogyakarta adalah destinasi wisata yang "Aman".

Meskipun secara keseluruhan wisatawan mancanegara merasa aman ketika berwisata di Kota Yogyakarta, tetapi masih dapat dilihat terdapat perbedaan nilai rata-rata dari setiap dimensi. Perbedaan tersebut dapat kemudian dianalisis kelebihan dan kekurangan Kota Yogyakarta dalam segi keselamatan dan keamanan wisata. Dari keempat dimensi, dimensi yang mendapat nilai rata-rata tertinggi adalah dimensi yang membahas terkait "Persepsi wisatawan terhadap keramahan masyarakat setempat" dengan nilai 3,32 dan termasuk dalam kategori "Sangat Aman". Menurut pendapat Batra (2008), ketidakramahan masyarakat dapat menyebabkan unsur ketakutan pada wisatawan seperti kekhawatiran berinteraksi dengan masyarakat lokal dan rasa takut diganggu karena perbedaan ras dan budaya.Dari data, dapat dilihat bahwa Kota Yogyakarta memiliki tingkat keramahan masyarakat yang tinggi sehingga tidak akan menimbulkan kekhawatiran seperti yang dinyatakan oleh Batra. Tingkat keramahan masyarakat ini juga merupakan sebuah keunggulan industri pariwisata bagi Kota Yogyakarta. Sedangkan untuk dimensi dengan nilai rata-rata terendah terdapat pada dimensi yang membahas terkait "Persepsi wisatawan terhadap keamanan dalam lalu lintas" dengan nilai 2,29 dan termasuk dalam kategori "Tidak Aman". Menurut Milman \& Bach (1999), keselamatan dalam lalu lintas akan mempengaruhi keinginan wisatawan untuk mengeksplorasi destinasi wisatawan di sebuah tempat. Dalam hal ini, adanya persepsi "TidakAman" wisatawan mancanegara terhadap keamanan dalam lalu lintas dapat membatasi mobilitas wisatawan ke destinasi wisata yang ada di Kota Yogyakarta. Berdasarkan hasil analisis tersebut, Kota Yogyakarta memerlukan perencanaan lalu lintas yang lebih mapan agar wisatawan mancanegara dapat merasa aman dalam menggunakan jalan atau berlalu lintas di Kota Yogyakarta.

Dimensi "Persepsi wisatawan secara umum terhadap Kota Yogyakarta" mendapatkan nilai rata-rata 2,95 dan termasuk dalam kategori "Aman". Selain sebagian wisatawan mancanegara merasa negara asalnya lebih aman, tidak ada item pernyataan yang jatuh pada kategori "Tidak Aman" atau "Sangat Tidak Aman". Ini menjadi sebuah tugas bagi pemerintah setempat untuk terus meningkatkan rasa Aman di Kota Yogyakarta agar dapat bersaing dengan negara lain. Dimensi "Persepsi wisatawan terhadap keselamatan dan keamanan wisata" juga termasuk dalam kategori "Aman". Namun, dari delapan item pernyataan, terdapat tiga item pernyataan yang berhubungan dengan polisi dan petugas keamanan termasuk dalam kategori "Tidak Aman". Hasil ini juga menunjukkan perlunya upaya polisi dan petugas keamanan dalam meningkatkan eksistensi dan efisiensinya agar dapat dipercaya wisatawan mancanegara.

Tabel 3. Persepsi wisatawan terhadap keselamatan dan keamanan wisata di Kota Yogyakarta

\begin{tabular}{|c|c|c|c|}
\hline No & Dimensi & $\begin{array}{l}\text { Mean } \\
\text { Score }\end{array}$ & Ket \\
\hline 1 & $\begin{array}{l}\text { Persepsi wisatawan } \\
\text { secara umum terhadap } \\
\text { Kota Yogyakarta }\end{array}$ & 2,95 & Aman \\
\hline 2 & $\begin{array}{l}\text { Persepsi wisatawan } \\
\text { terhadap keselamatan } \\
\text { dan keamanan wisata }\end{array}$ & 2,82 & Aman \\
\hline 3 & $\begin{array}{l}\text { Persepsi wisatawan terhadap } \\
\text { keamanan dalam lalu lintas }\end{array}$ & 2,29 & $\begin{array}{l}\text { Tidak } \\
\text { Aman }\end{array}$ \\
\hline 4 & $\begin{array}{l}\text { Persepsi wisatawan } \\
\text { terhadap keramahan } \\
\text { masyarakat setempat }\end{array}$ & 3,32 & $\begin{array}{l}\text { Sangat } \\
\text { Aman }\end{array}$ \\
\hline 5 & $\begin{array}{c}\text { Keselamatan dan keamanan } \\
\text { wisata Kota Yogyakarta }\end{array}$ & 2,85 & Aman \\
\hline
\end{tabular}

\subsection{Perbedaan Persepsi Wisatawan Perempuan dan Laki-laki Mancanegara Terhadap Keselamatan dan Keamanan Wisata di Kota Yogyakarta}

Dilihat dari perspektif gender, dapat dilihat bahwa wisatawan laki-laki mancanegara memiliki nilai rata-rata yang lebih tinggi dibandingkan wisatawan perempuan mancanegara dengan masing-masing angka 2,91 dan 2,76. Kedua gender termasuk dalam kategori "Aman". Dari keempat dimensi dalam penelitian ini, wisatawan perempuan mancanegara hanya merasa lebih aman ketika menggunakan lalu lintas di Kota Yogyakarta sedangkan wisatawan laki-laki mancanegara merasa lebih aman di tiga dimensi lainnya. Data ini menunjukkan wisatawan 
Tabel 4. Perbedaan persepsi wisatawan perempuan dan laki-laki mancanegara terhadap keselamatan dan keamanan wisata di Kota Yogyakarta

\begin{tabular}{|c|c|c|c|c|c|c|c|c|}
\hline No & \multicolumn{3}{|c|}{ Pernyataan } & GU & KK & $\mathbf{L L}$ & KM & Mean \\
\hline \multicolumn{9}{|c|}{ Gender } \\
\hline 1 & \multicolumn{2}{|c|}{ Laki-laki } & mean & $3,10(\mathrm{~A})$ & $2,93(\mathrm{~A})$ & 2,25 (TA) & $3,37(\mathrm{SA})$ & 2,91 (A) \\
\hline 2 & \multicolumn{2}{|c|}{ Perempuan } & mean & $2,81(\mathrm{~A})$ & $2,60(\mathrm{~A})$ & 2,3 (TA) & $3,30(\mathrm{SA})$ & 2,76 (A) \\
\hline \multicolumn{9}{|c|}{ Benua Asal } \\
\hline \multirow{2}{*}{1} & \multirow{2}{*}{ Afrika } & LK & \multirow{2}{*}{ mean } & INV & INV & INV & INV & INV \\
\hline & & PR & & $2,80(\mathrm{~A})$ & $2,75(\mathrm{~A})$ & $2,50(\mathrm{TA})$ & 2,83 (A) & $2,72(\mathrm{~A})$ \\
\hline \multirow{2}{*}{2} & \multirow{2}{*}{ Amerika } & LK & \multirow{2}{*}{ mean } & $3,04(\mathrm{~A})$ & $2,70(\mathrm{~A})$ & 1,90 (TA) & $3,38(\mathrm{SA})$ & $2,76(\mathrm{~A})$ \\
\hline & & PR & & $2,54(\mathrm{~A})$ & $2,68(\mathrm{~A})$ & $2,61(\mathrm{TA})$ & $3,43(\mathrm{SA})$ & $2,82(\mathrm{~A})$ \\
\hline \multirow{2}{*}{3} & \multirow{2}{*}{ Asia } & LK & \multirow{2}{*}{ mean } & $2,86(\mathrm{~A})$ & $2,99(\mathrm{~A})$ & 2,35 (TA) & $3,23(\mathrm{~A})$ & 2,86 (A) \\
\hline & & PR & & $2,70(\mathrm{~A})$ & $2,44(\mathrm{~A})$ & 2,31 (TA) & $3,08(\mathrm{~A})$ & $2,63(\mathrm{~A})$ \\
\hline \multirow{2}{*}{4} & \multirow{2}{*}{ Australia } & LK & \multirow{2}{*}{ mean } & $3,27(\mathrm{~A})$ & $2,98(\mathrm{~A})$ & 2,21 (TA) & $3,36(\mathrm{SA})$ & $2.96(\mathrm{~A})$ \\
\hline & & PR & & $3,00(\mathrm{~A})$ & $2,25(\mathrm{~A})$ & $2,00(\mathrm{TA})$ & $3,50(\mathrm{SA})$ & 2.69 (A) \\
\hline \multirow{2}{*}{5} & \multirow{2}{*}{ Eropa } & LK & \multirow{2}{*}{ mean } & $3,14(\mathrm{~A})$ & $2,97(\mathrm{~A})$ & 2,28 (TA) & $3,39(\mathrm{SA})$ & 2.95 (A) \\
\hline & & PR & & $2,89(\mathrm{~A})$ & $2,79(\mathrm{~A})$ & $2,30(\mathrm{TA})$ & $3,34(\mathrm{SA})$ & $2.83(\mathrm{~A})$ \\
\hline \multicolumn{9}{|c|}{ Usia } \\
\hline \multirow{2}{*}{1} & \multirow{2}{*}{17} & LK & & INV & INV & INV & INV & INV \\
\hline & & PR & mean & $2,80(\mathrm{~A})$ & $2,00(\mathrm{~A})$ & $3,00(\mathrm{~A})$ & $3,67(\mathrm{SA})$ & 2,87 (A) \\
\hline 0 & 102 & LK & & $3,12(\mathrm{~A})$ & $2,97(\mathrm{~A})$ & 2.29 (TA) & $3,41(\mathrm{SA})$ & $2,95(\mathrm{~A})$ \\
\hline 2 & $18-24$ & $\mathrm{PR}$ & mean & $2,68(\mathrm{~A})$ & $2,60(\mathrm{~A})$ & 2,28 (TA) & $3,29(\mathrm{SA})$ & $2,71(\mathrm{~A})$ \\
\hline & 2521 & LK & & $3,02(\mathrm{~A})$ & $2,88(\mathrm{~A})$ & 2.32 (TA) & $3,33(\mathrm{SA})$ & $2.89(\mathrm{~A})$ \\
\hline 3 & $25-31$ & PR & mean & $2,83(\mathrm{~A})$ & $2,72(\mathrm{~A})$ & 2,42 (TA) & $3,30(\mathrm{SA})$ & 2.82 (A) \\
\hline & & LK & & $3,04(\mathrm{~A})$ & $2,89(\mathrm{~A})$ & 2,04 (TA) & $3,32(\mathrm{SA})$ & $2.82(\mathrm{~A})$ \\
\hline 4 & $32-38$ & PR & mean & $3,30(\mathrm{~A})$ & $3,03(\mathrm{~A})$ & $2,19(\mathrm{TA})$ & $3,42(\mathrm{SA})$ & 2.99 (A) \\
\hline 5 & $30-15$ & LK & meon & $3,10(\mathrm{~A})$ & $2,94(\mathrm{~A})$ & 2,75 (TA) & $3,42(\mathrm{SA})$ & $3.05(\mathrm{~A})$ \\
\hline 3 & $39-45$ & PR & mean & INV & INV & INV & INV & INV \\
\hline & $56-0$ & LK & & 3,07 (A) & $2,88(\mathrm{~A})$ & $2,67(\mathrm{~A})$ & $3,33(\mathrm{SA})$ & 2.99 (A) \\
\hline 6 & $40-52$ & $\mathrm{PR}$ & mean & $2,87(\mathrm{~A})$ & $2,92(\mathrm{~A})$ & 2,42 (TA) & $3,28(\mathrm{SA})$ & $2.87(\mathrm{~A})$ \\
\hline 7 & 53 & LK & mogn & $3,47 \quad(\mathrm{~A})$ & $3,21(\mathrm{~A})$ & 2,17 (TA) & $3,50(\mathrm{SA})$ & $3.09(\mathrm{~A})$ \\
\hline 1 & 53 & PR & mean & $3,00(\mathrm{~A})$ & $3,13(\mathrm{~A})$ & $2,13(\mathrm{TA})$ & $3,25(\mathrm{~A})$ & $2.88(\mathrm{~A})$ \\
\hline & & & & Lama & gal & & & \\
\hline 1 & 13 & LK & mon & $3,05(\mathrm{~A})$ & $2,93(\mathrm{~A})$ & 2,20 (TA) & 3,40 (SA) & $2,90(\mathrm{~A})$ \\
\hline 1 & $1-3$ & PR & mean & $2,83(\mathrm{~A})$ & $2,81(\mathrm{~A})$ & 2,35 (TA) & $3,33(\mathrm{SA})$ & 2,83 (A) \\
\hline 2 & 16 & LK & mon & 3,17 (A) & $3,14(\mathrm{~A})$ & $2,61(\mathrm{~A})$ & $3,36(\mathrm{SA})$ & 3,07 (A) \\
\hline 2 & $4-6$ & PR & mean & $2,71(\mathrm{~A})$ & $2,61(\mathrm{~A})$ & 2,32 (TA) & $3,38(\mathrm{SA})$ & $2,76(\mathrm{~A})$ \\
\hline 3 & 70 & LK & mean & $3,00(\mathrm{~A})$ & $2,63(\mathrm{~A})$ & 2,25 (TA) & $3,25(\mathrm{~A})$ & $2,78(\mathrm{~A})$ \\
\hline 3 & $1-9$ & PR & mean & $3,00(\mathrm{~A})$ & $2,67(\mathrm{~A})$ & 2,50 (TA) & $3,11(\mathrm{~A})$ & $2,82(\mathrm{~A})$ \\
\hline 4 & 10-10 & LK & mean & INV & INV & INV & INV & INV \\
\hline 4 & $10-12$ & PR & mean & INV & INV & INV & INV & INV) \\
\hline 5 & $13-15$ & LK & mean & $2,95(\mathrm{~A})$ & $2,88(\mathrm{~A})$ & 2,25 (TA) & $3,42(\mathrm{SA})$ & $2,88(\mathrm{~A})$ \\
\hline 5 & $13-15$ & PR & mean & $2,80(\mathrm{~A})$ & $2,75(\mathrm{~A})$ & 2,50 (TA) & $3,00(\mathrm{~A})$ & $2,76(\mathrm{~A})$ \\
\hline 6 & 16 & LK & mean & $2,80(\mathrm{~A})$ & $3,04(\mathrm{~A})$ & 2,08 (TA) & 3,19 (A) & $2,78(\mathrm{~A})$ \\
\hline 6 & 10 & PR & mean & $2,80(\mathrm{~A})$ & 2,16 (TA) & 2,19 (TA) & $3,13(\mathrm{~A})$ & 2,57 (A) \\
\hline
\end{tabular}


perempuan mancanegara ternyata merasa lebih rentan atau tidak aman jika dibandingkan dengan wisatawan laki-laki mancanegara.

Dari perspektif benua, hasil penelitian mengungkapkan bahwa wisatawan laki-laki mancanegara dari sebagian besar benua merasa lebih aman dari wisatawan perempuan mancanegara, kecuali dari Benua Amerika yang wisatawan perempuan mancanegara memiliki nilai rata-rata total 2,82 dan wisatawan laki-laki memiliki nilai rata-rata total 2,76 , hanya selisih 0,06 . Nilai rata-rata wisatawan laki-laki Eropa terhadap keselamatan dan keamanan wisata di Kota Yogyakarta adalah 2,95, lebih tinggi dari wisatawan perempuan Eropa yang dengan angka 2,84. Perbedaan angka yang lebih jauh juga dapat dilihat dari wisatawan dari Benua Asia yang wisatawan laki-lakinya memiliki nilai rata-rata 2,86 sedangkan wisatawan perempuan memiliki nilai rata-rata 2,63. Benua Australia hanya diwakili oleh seorang perempuan dari tujuh orang wisatawan dan Benua Afrika hanya diwakili oleh seorang perempuan dari seluruh wisatawan Afrika, maka peneliti tidak menyimpulkan kedua benua tersebut dengan alasan tidak memiliki representasi gender yang seimbang.

Berdasarkan usia, data menunjukkan bahwa semakin tinggi usia wisatawan, terdapat kecenderungan semakin tinggi pula nilai rata-ratanya dalam mempersepsi keselamatan dan keamanan di Kota Yogyakarta. Data juga mengungkapkan bahwa wisatawan laki-laki yang berasal dari berbagai kelompok usia cenderung memiliki nilai rata-rata yang lebih tinggi daripada wisatawan perempuan. Hanya terdapat satu kelompok usia yang menunjukkan hasil yang sebaliknya yaitu pada kelompok usia 32-38 dengan selisih nilai 0,17 . Wisatawan perempuan mancanegara pada kelompok ini memiliki nilai rata-rata 2,99 sedangkan wisatawan laki-laki mancanegara hanya memiliki nilai rata-rata 2,82. Kelompok usia 17 dan 39-45 tidak dapat diidentifikasi karena tidak memiliki representasi dari salah satu gender. Data ini membuktikan bahwa dari karakteristik usia, wisatawan laki-laki mancanegara masih merasa lebih aman jika dibandingkan dengan wisatawan perempuan mancanegara.

Analisis berdasarkan lama tinggal menunjukkan bahwa semakin lama wisatawan menetap di Kota Yogyakarta, terdapat kecenderungan semakin buruk persepsinya terhadap keramahan masyarakat setempat. Hal ini mungkin berhubungan dengan lamanya wisatawan berinteraksi dengan masyarakat setempat. Hasil analisis berdasarkan gender mengungkapkan bahwa wisatawan laki-laki cenderung memiliki nilai rata-rata yang lebih tinggi dari wisatawan perempuan, kecuali pada kelompok rentang lama tinggal 4-6 hari yang menunjukan angka yang berbanding terbalik dengan selisih 0,02 . Hal ini menunjukkan bahwa wisatawan laki-laki mancanegara dari berbagai kelompok rentang lama tinggal memiliki persepsi yang lebih baik dalam keramahan masyarakat setempat dibandingkan wisatawan perempuan mancanegara. Dilihat secara rinci, nilai rata-rata tertinggi terdapat pada item KM 4 yang menanyakan rasa nyaman wisatawan terhadap keramahan penduduk lokal. Namun, jika dilihat dari perspektif gender, tidak terdapat perbedaan signifikan.

\section{Kesimpulan}

\subsection{Kesimpulan}

Keselamatan dan keamanan wisata merupakan salah satu unsur yang paling penting dalam industri pariwisata karena dapat mempengaruhi jumlah kunjungan wisatawan ke suatu destinasi (George, 2002: 575:585). Persepsi wisatawan yang buruk terhadap suatu destinasi akan menyebabkan wisatawan enggan untuk mengunjungi destinasi tersebut (Ryan, 1993: 173-183). Dalam kajian keselamatan dan keamanan wisata, gender sering menjadi sebuah perdebatan karena terdapat ahli yang menyatakan faktor gender dapat mempengaruhi wisatawan dalam mempersepsi keselamatan dan keamanan wisata (Resinger dan Crotts, 2009: 800; Gustafson, 1998: 805-801) tetapi juga terdapat ahli yang menyatakan gender tidak mempengaruhi persepsi keselamatan dan keamanan wisata (Lepp \& Gibson, 20013: 606-624; Stants dkk, 2006: 121132).

Kota Yogyakarta merupakan ibu kota dari Provinsi Daerah Istimewa Yogyakarta dan merupakan kota yang menyumbangkan wisatawan mancanegara terbanyak kepada Provinsi DIY (Statistik Kepariwisataan Yogyakarta 2017). Persepsi keselamatan dan keamanan wisata terhadap Kota Yogyakarta sangat penting karena akan secara langsung mempengaruhi jumlah kunjungan 
wisatawan ke Provinsi DIY dan Indonesia. Namun, sampai saat ini belum terdapat penelitian terkait persepsi keselamatan dan keamanan wisata terutama dari sudut pandang gender. Oleh sebab itu, dibutuhkan sebuah penelitian yang ditujukan untuk mengkaji perbedaan persepsi wisatawan perempuan dan laki-laki mancanegara terhadap keselamatan dan keamanan wisata di Kota Yogyakarta.

Hasil penelitian menunjukkan bahwa persepsi responden wisatawan mancanegara terhadap keselamatan dan keamanan wisata di Kota Yogyakarta adalah "Aman" dengan nilai ratarata 2,85. Meskipun demikian, hasil tersebut tidak dapat digeneralisasikan karena terdapat perbedaan persepsi pada setiap dimensi. Data menunjukkan bahwa dimensi yang membahas terkait "persepsi wisatawan terhadap keamanan dalam lalu lintas" mendapatkan nilai rata-rata terendah dengan angka 2,29 dan termasuk dalam kategori "Tidak Aman", sedangkan dimensi yang membahas tentang "persepsi wisatawan terhadap keramahan masyarakat setempat" mendapatkan nilai rata-rata tertinggi dengan angka 3,32 dan termasuk dalam kategori "Sangat Aman". Untuk dimensi yang membahas "persepsi wisatawan secara umum terhadap Kota Yogyakarta" dan "persepsi wisatawan mancanegara terhadap keselamatan dan keamanan wisata" termasuk dalam kategori "Aman" dengan nilai rata-rata 2,95 dan 2,82 secara berurutan.

Dari perspektif karakteristik wisatawan mancanegara, dari analisis diketahui wisatawan laki-laki mancanegara cenderung merasa lebih aman untuk berwisata di Kota Yogyakarta dengan nilai rata-rata 2,91 pada persepsi terhadap keselamatan dan keamanan wisata secara keseluruhan, sedangkan wisatawan perempuan mancanegara memiliki nilai rata-rata yang lebih rendah pada angka 2,76. Dari karakteristik wisatawan yang berupa asal benua, usia, dan lama tinggal, hasil juga menunjukkan bahwa wisatawan laki-laki mancanegara memiliki nilai rata-rata yang lebih tinggi jika dibandingkan dengan wisatawan mancanegara perempuan.

\subsection{Saran}

Berdasarkan hasil pembahasan dalam penelitian ini, peneliti memiliki beberapa saran untuk penelitian selanjutnya:

Walau target responden dalam penelitian ini merupakan wisatawan mancanegara, terdapat banyak wisatawan mancanegara yang tidak terepresentasi dalam penelitian ini seperti wisatawan dari Afrika, Timur Tengah, Amerika Selatan dan Asia Selatan. Hal ini dikarenakan setiap destinasi wisata tidak memiliki data terkait persentase wisatawan mancanegara yang berkunjung sehingga peneliti tidak dapat menentukan proporsi wisatawan mancanegara berdasarkan benua asal. Kuesioner yang dirancang juga hanya tersedia dalam Bahasa Inggris sehingga beberapa wisatawan dari Perancis, Kolombia, Jepang, dan Tiongkok menolak turut berpartisipasi dalam penelitian ini.

Kuesioner dalam penelitian ini menggunakan skala likert dengan empat tingkat yaitu Sangat Tidak Setuju, Tidak Setuju, Setuju, dan Sangat Setuju dan tidak menggunakan netral. Namun, terdapat banyak responden yang menandakan opininya pada garis antara Tidak Setuju dan Setuju untuk dan mengatakan bersikap netral dalam item pernyataan tertentu sehingga data tidak dapat digunakan. Peneliti menyarankan untuk menggunakan skala likert lima tingkat untuk penelitian ke depan agar menghindari data yang tidak valid.

Terdapat tidak sedikit wisatawan mancanegara yang telah berwisata di beberapa kabupaten di DIY maupun Indonesia sehingga perspektif yang diopinikan tidak murni mewakili Kota Yogyakarta. Penelitian selanjutnya dapat dilakukan dengan lokus yang lebih luas seperti DIY maupun indonesia untuk mengetahui persepsi wisatawan mancanegara terhadap keselamatan dan keamanan wisata yang lebih luas.

Penelitian selanjutnya juga dapat mengeksplorasi hubungan antara karakteristik wisatawan dengan dimensi seperti hubungan lama tinggal dengan keramahan masyarakat setempat atau hubungan usia dengan keamanan dalam lalu lintas. Hal tersebut diharapkan dapat menemukan korelasi antar variabel yang lebih rinci dan jelas.

\section{Catatan Akhir}

1) diakses dari: http://www2.unwto.org/publication/ tourist-safety-and-security-practical-measuresdestinations tanggal 2 April 2018 Pukul 17:54 WIB

\section{Daftar Pustaka}

Amir, A. F., Ismail, M. N. I., \& See, T. P. (2015). 
Sustainable tourist environment: Perception of international women travelers on safety and security in Kuala Lumpur. Procedia-Social and Behavioral Sciences. 168: 123-133.

Altares, S. P., Copo, A. R. I., Gabuyo, Y. A., (2003). Elementary Statistics: A Modern Approach. Manila: Rex Book Store.

Altinay, L. \& Paraskevas, A. (2008). Planning research in hospitality \& tourism. Oxford: Elsevier.

Badan Pusat Statistil. (2016). Statistik Kriminalitas Indonesia 2016: Badan Pusat Statistik.

Batra, A. (2008). Foreign tourists' perception towards personal safety and potential crime while visiting Bangkok. Anatolia - An International Journal of Tourism and Hospitality Research. 19(1): 89-101.

Barker, M., Page, S. J., \& Meyer, D. (2003). Urban visitor perceptions of safety during a special event. Journal of Travel Research. 41(4): 355361.

Brongtodiningrat, K. P. H. (1978). Arti Kraton Yogyakarta. Yogyakarta: Museum Kraton Yogyakarta.

Bogdan, R. C. \& Biklen. (1982). Qualitative Research for Education Theory and Methods: An Introduction to Theories and Methods. Boston: Allyn and Bacon.

Chesney-Lind, M. (1986). Women and Crime: The Female Offender. Journal of Women in Culture and Society. 12(1): 78-96.

Cooper, C., Fletcher, J., Gilbert, D., Fyall, A. \& Wanhill, S. (2005). Tourism: Principles and practice. London: Pearson Education.

Crotti R., Misrahi T. (2017). The Travel \& Tourism Competitiveness Report 2017. World Economic Forum. Geneva, Switzerland.

Daliman, A. (2012). Makna Sengkalan Sebagai Dinamika Kesadaran Historis: Kajian Filosofis Historis Keraton Yogyakarta. Yogyakarta: Penerbit Ombak

Dinas Pariwisata. (2017) Statistik Kepariwisataan Yogyakarta 2017: Dinas Pariwisata Daerah Istimewa Yogyakarta.

Enz, C. A. (2009). The physical safety and security features of US hotels. Cornell Hospitality Quarterly. 50(4): 553-560.

Fujii, E. T. \& Mak, J. (1979). The impact of alternative regional development strategies on crime rates: tourism vs. agriculture in Hawaii. Annals of Regional Science. 13(3): 42-56.

George, R. (2002). Tourists' Perceptions of Safety and Security while Visiting Cape Town. Tourism Management. 24(5):575-585.

Gustafson, P. E. (1998). Gender differences in risk perception: Theoretical and methodological perspectives. Risk Analysis. 18(6): 805-811.

Chesney-Lind, M., \& Lind, I. Y. (1986). Visitors as victims: Crimes against tourists in Hawaii. Annals of Tourism Research. 13: 167-191.

Jensen, S. (2017). What Determines the Choice of Tourist Destination? The Case of Denmark. Business and Management Horizons. 5(2): 112-124.

Kovari, I. \& Zimányi, K. (2011). Safety and Security in the Age of Global Tourism (The changing role and conception of Safety and Security in Tourism). APSTRACT. 5(3-4): 1-3.

Laporan Kinerja Dinas Pariwisata Tahun Anggaran 2018. Dinas Pariwisata Kota Yogyakarta.

Lepp, A. \& Gibson, H. (2003). Tourist roles, perceived risk and international tourism. Annals of Tourism Research. 30(3): 606-624.

McLain, L. (1981). The EEOC Sexual Harassment Guidelines: Welcome Advances under Title VII? University of Baltimore Law Review. 10(2): Article 4

Mansfeld, Y. (2006). The Role of Security Information in Tourism Crisis Management: The Missing Link. In Mansfeld, Y, Pizam, A. (Eds.), Tourism, security and safety from theory to practice, Burlington, MA: Elsevier, Butterworth-Heinemann.pp.271-2.

Mansfeld, Y., \& Pizam, A. (Eds.). (2006). Tourism, security and safety. London: Routledge.

Mathieson, A. \& Wall, G., (1982). Tourism, economic, physical and social impacts. London: Longman.

Milman, A., \& Bach, S. (1999). The impact of security devices on tourists' perceived safety: The central Florida example. Journal of Hospitality and Tourism Research. 23(4): 371-386.

Park, K. \& Reisinger, Y. (2010). Differences in the perceived influence of natural disasters and travel risk on international travel. Tourism Geographies. 12(1): $1-24$

Pearce, P. L. (1988). The Ulysses Factor: Evaluating Visitors in Tourist Settings. New York: Springer.

Pratama, S.A. (2016). Analisis Tingkat Rasa Aman Wisatawan Domestik Terhadap Layanan Polisi Pariwisata Di Kawasan Malioboro Yogyakarta. Skripsi. Fakultas Ilmu Budaya. Universitas Gadjah Mada.

Raksapati, A. (2011). Pengaruh Citra Keamanan Destinasi Terhadap Kunjungan Wisatawan Nusantara Ke Yogyakarta Tahun 2011. Tesis. Pusat Studi Pariwisata. Universitas Gadjah Mada.

Reisinger, Y. \& Crotts, J. C. (2009). The influence of gender on travel risk perceptions, safety, and travel intentions. Tourism Analysis. 14(6): 793807.

Ryan, C. (1993). Crime, Violence, Terrorism and Tourism. An Accidental or Intrinsic Relationship? 
Tourism Management. 14(3): 173-183.

Santosa, Revianto Budi. (2007). Kota Gede: Life Between Walls. Jakarta: PT Gramedia Pustaka Utama.

Shin, Y.S. (2005). Safety, security and peace tourism: The case of the DMZ area. Asia Pacific Journal of Tourism Research. 10(4): 411-426.

Umar, H. (1998). Riset Sumber Daya Manusia. Jakarta: Gramedia Pustaka Utama.

United Nation. (2010). International Recommendations for Tourism Statistics 2008. Series M No.83/ Rev.1. New York: United Nation.

Staats, S., Panek, P., \& Cosmar, D. (2006). Predicting travel attitudes among university faculty after 9/11. The Journal of Psychology. 140(2): 121132.

Williams, A. M. \& Bala z, V. (2013). Tourism, risk tolerance and competences: Travel organization and tourism hazards. Tourism Management. 35: 209-221.

World Economic Forum. (2017). The Travel \& Tourism Competitiveness Report 2017. Geneva: World Economic Forum.

World Tourism Organization. (2004). A Guidebook: Indicators of Sustainable Development for Tourism Destinations. Madrid: World Tourism Organisation.

Yang, E. C. L., Khoo-Lattimore, C., \& Arcodia, C. (2017). A systematic literature review of risk and gender research in tourism. Tourism Management. 58: 89-100.

Yusuf, M. (2014). Metodologi Penelitian Kuantitatif, Kualitatif \& Penelitian Gabungan. Jakarta: Prenadamedia.

Alwi, T. (2017). Jelang Natal dan Tahun Baru, Polda DIY Imbau Masyarakat Selalu Waspada. Jogja TribunNews http://jogja.tribunnews. com/2017/12/21/jelang-natal-dan-tahun-barupolda-diy-imbau-masyarakat-selalu-waspada. Diakses pada 8 Maret 2018 pukul 20.54 WIB.

Anonim. (2018) ANEV KAMTIBMAS POLDA DIY di tahun 2018..http://jogja.polri.go.id/ website/?page $\mathrm{id}=22148$ Diakses pada 7 May 2019 pukul 20.50 WIB.

Anonim. (2018). Foreign Travel Advice. GOV.UK. https://www.gov.uk/foreign-travel-advice/ indonesia Diakses pada 3 April 2018 pukul 20.50 WIB.

Anonim. (2017). Indonesia. http://smartraveller.gov.au/ Countries /asia/south-east/pages/indonesia.aspx Diakses pada 4 April 2018 pukul 10.30 WIB.

Anonim. (tanpa tahun). Kondisi Geografis Kota Yogyakarta. Portal Pemerintah Kota Yogyakarta. https://travel.state.gov/content/travel/en/ traveladvisories/traveladvisories/indonesiatravel-advisory.html. Diakses pada 3 April 2018 pukul 15.32 WIB.

Anonim. (tanpa tahun). Indonesia Travel Advisory. Travel.State.Gov (U.S Department of State - Bureau of Consular Affairs). https://travel. state.gov/content/ travel/en/traveladvisories/ traveladvisories/indonesia-travel-advisory.html Diakses pada 3 April 2018 pukul 15.32 WIB.

Anonim. (tanpa tahun). Outbound Travel Alert. Security Bureau: The Government of the Hong Kong Special Administrative Region.http://www. sb.gov.hk/eng/ ota/note-Indonesia.htm Diakses pada 3 April pukul 21.03 WIB.

Anonim. (2017). 3 Tahun Jokowi-JK, Pariwisata Sumbang Devisa Terbesar Kedua. Kominfo. https://kominfo.go.id/content/detail/11033/ pariwisata-sumbang-devisa-terbesar-kedua/0/ berita. Diakses pada 8 Maret 2018 pukul 20.46 WIB.

Badan Pusat Statistik. (2017). Distribusi PDRB Kota Yogyakarta Menurut Lapangan Usaha Atas Dasar Harga Berlaku (Persen), 2010-2017. https://jogjakota.bps.go .id/ dynamictable/2019/02/13/43/distribusi-pdrbkota-yogyakarta-menurut-lapangan-usaha-atasdasar-harga-berlaku-persen-2010-2017.html. Diakses pada tanggal 9 Mei 2019 pukul 10. 27 WIB.

Polda D.I. Yogyakarta. (2018). Beri Rasa Aman, Polisi Pariwisata Patroli ke Obyek Wisata. http://jogja. polri.go.id/website/?p=17869. Diakses pada 6 November 2018 pukul 00.05 WIB.

Putera, A. D.. (2018). Adisujipto, Bandara Paling "Crowded" dengan Kapasitas Terbatas. https:// ekonomi.kompas.com/read/2018/01/27/1249 43526/adisutjipto-bandara-paling-crowdeddengan-kapasitas-terbatas . Diakses pada 27 Maret 2018. pukul 11.00 WIB.

Sankhyaadi, A. (2018). Dinpar Daerah Istimewa Yogyakarta Optimis Target Wisman 2018 Tercapai. https://kumparan.com/@,kumparan travel/dinpardaerah-istimewa-yogyakarta-optimis-targetwisman-2018-tercapai-1542113990421479011. Diakses pada 30 Mei 2019 pukul 16.58 WIB.

UNWTO. (1996). TOURIST SAFETY AND SECURITY Practical Measures for Destinations. http://www. safecoastaltourism.org/article/tourist-safety-a ndsecurity-practical-measures-destinations. Diakses pada 27 Maret 2018. pukul 11.00 WIB.

Wamad, S. (2017). Kalahkan Minyak dan Gas, Pariwisata Penyumbang Devisa Nomor 2 RI. Travel Detik. https://travel.detik.com/travelnews/d-3646924/kalahkan-minyak-dan-gas- 
pariwisata-penyumbang-devisa-nomor-2-ri. Diakses pada 3 April 2018 ukul 17.25 WIB.

Wardhani, C. M. (2018). LBH Yogyakarta Terima Banyak Kasus Kekerasan Seksual pada Perempuan. http://jogja.tribunnews.com/2018/09/05/lbhyogyakarta-terima-banyak-kasus-kekerasanseksual-pada-perempuan. Diakses pada tanggal 30 Desember 2018 pukul 19.30 WIB.

Wardhani, C. M. (2018). LBH Yogyakarta Terima Banyak Kasus Kekerasan Seksual pada Perempuan. Seorang Turis Jadi Korban Pelecehan Seksual di Prawirotaman. http://jogja.tribunnews. com/2018/11/ 06/seorang-turis-jadi-korbanpelecehan-seksual-di-prawirotaman. Diakses pada tanggal 30 Desember 2018 pukul 19.51 WIB.

\section{Wawancara}

Wawancara Ibu Amieroel Pakoeningrat, Sleman, Daerah Istimewa Yogyakarta, 12 Juni 2019, Pukul 08.15 WIB

Wawancara Bapak Warisman, Sleman, Daerah Istimewa Yogyakarta, 13 Juni 2019, Pukul 08.44 WIB Wawancara Bapak Niko, Sleman, Daerah Istimewa Yogyakarta, 12 Juni 2019, Pukul 09.02 WIB 